The Geneva Papers on Risk and Insurance, 17 (No. 63, April 1992), 232-243

\title{
The Development of Insurance Markets of Developing Countries: UNCTAD's Activities in the Field of Human Resources Development
}

\author{
by Michel Couroux* and J. François Outreville*
}

\section{Introduction}

Insurance, like other financial services, has grown in quantitative importance as part of the general development of financial institutions, but has also become qualitatively more important, due to the increase of risks and uncertainties in most societies. However, owing to the great diversity in the political, economic and social environment in which insurance markets have evolved, and the historical factors that have influenced the character of insurance in each country, it is not surprising to see that no two insurance markets especially in developing countries are identical.

Despite the differences of several years, and even decades, between the dates when some developing countries established their national insurance markets, the stage of development of those markets only rarely indicates when they were established. In fact, except in a few cases of a few very large insurance markets in the Third World, the rate of development of most local markets before and during the 1960 s and 1970 s was very slow indeed. It was only when the entire Third World accepted as a basic development strategy the establishment of national markets, including domestic insurance companies, that such markets became truly national and began to play their role in the development process.

Today, although the share of total insurance premiums generated in developing countries remains at a low figurc, the importance of the relationship between insurance development and economic growth has been well recognized and emphasized in the field of economic development. The study of total premium volume generated in different countries demonstrates a high income-elasticity of the demand for insurance. Graphic analysis (figure 1) makes it possible to verify that the amount of premium written per head adjust fairly well to a function of the gross domestic product per head of population.

The insurance markets of developing countries have not yet attained the size or sophistication which characterize the insurance markets of most of the developed countries.

* UNCTAD, Geneva. The views expressed in this document do not necessarily reflect those of the UNCTAD Secretariat. 


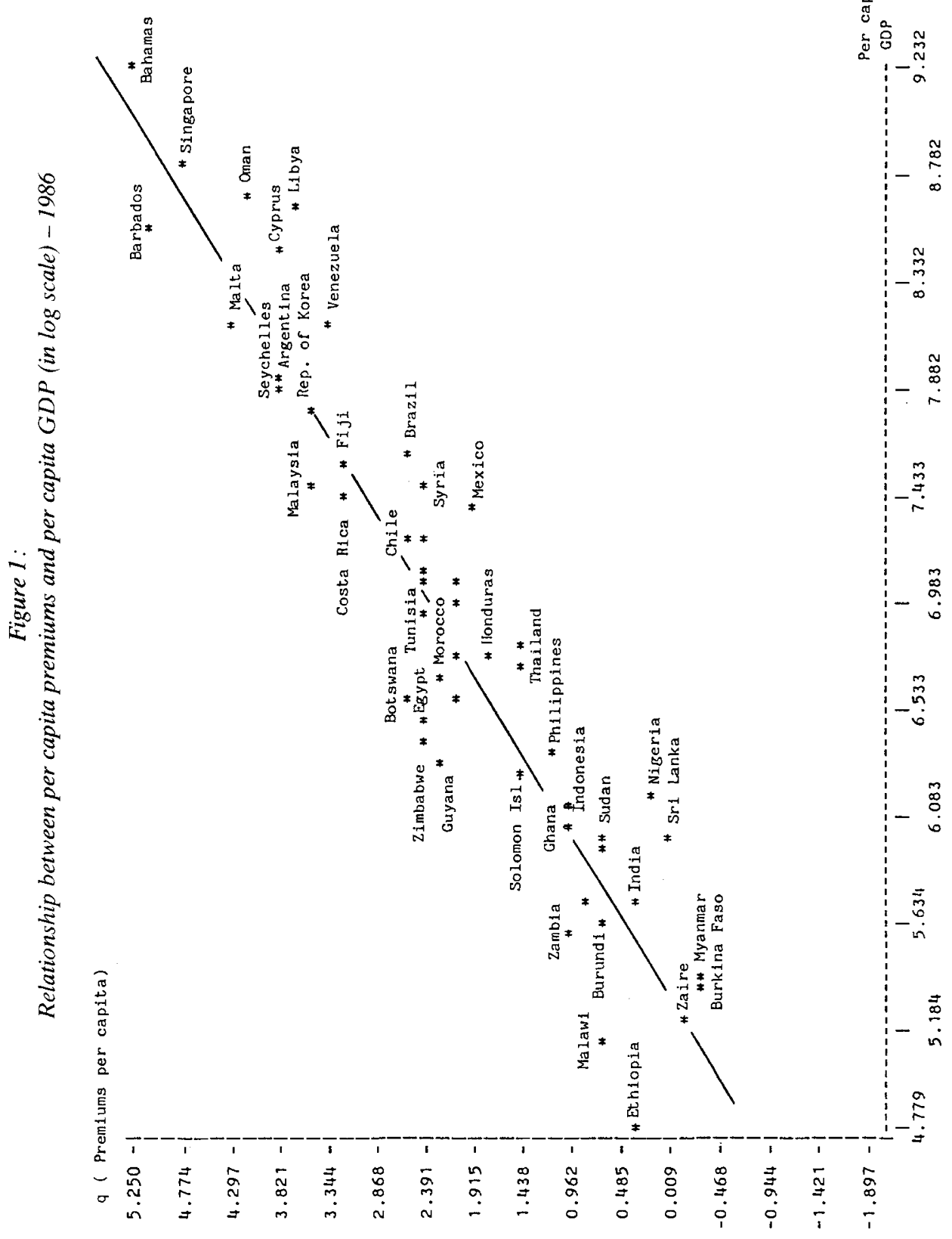


However, one can now observe that regardless of the cause of changes in developing countries' insurance markets, generally speaking, there has been great progress and that some other benefits like greater cooperation among countries seem to have resulted in a better understanding of the need for common grounds for action. The purpose of this paper is to review the role of UNCTAD in the development of insurance markets of developing countries.

\section{The activities of UNCTAD in the field of insurance and reinsurance}

Within the United Nations family of organizations, UNCTAD is the only one which includes insurance in its regular programme of work, and most insurance-related activities are carried out under the auspices of the Insurance Programme.

\subsection{What is UNCTAD?}

The First United Nations Conference on Trade and Development held in Geneva in 1964, led to the establishment of UNCTAD as a permanent organ of the General Assembly with the mandate of promoting international trade, particularly that of developing countries, with a view to accelerating their economic development.

The Conference, which meets about every four years, is the supreme body of the organization and is responsible for carrying out the principal functions entrusted to it by the General Assembly. Continuity of work between the Conference sessions is assumed by the Trade and Development Board, which has six main committees: Commodities, Manufactures, Invisibles and Financing related to Trade (CIFT), Shipping, Transfer of Technology and Economic Cooperation among Developing Countries. The CIFT is responsible for insurance and reinsurance issues and within the UNCTAD secretariat, the Insurance Programme is responsible for dealing with the insurance-related aspects of the Committee's work.

Two UNCTAD resolutions are of importance here.' The first adopted in 1964 formalized the belief that "a sound national insurance and reinsurance market is an essential characteristic of economic growth" (recommendation A.IV.23). This recommendation called upon developed countries to: (1) give their full co-operation to the developing countries to encourage and strengthen their national insurance and reinsurance markets; (2) continue and increase the technical assistance and training facilities they provide. The recommendation further stipulates that technical reserves and guarantee deposits of insurance and reinsurance companies or institutions should be invested in the country where the premium arises and calls on developed countries to encourage such investment by removing all obstacles to the achievement of this aim.

The second resolution, resolution 42 (III) adopted without dissent in 1972, was addressed more to the developing countries and invited them to take a series of measures geared to promote two objectives. The first was the need to minimize, to the extent feasible, the dependence of developing countries on international insurers and reinsurers. Second, it was implicitly recognized that total independence of foreign insurance and reinsurance markets was not possible and, therefore, that efforts should be made to secure the most appropriate terms and conditions at the lowest cost commensurate with the risks involved.

\footnotetext{
1 See the complete text of all the resolutions in The Activities of UNCTAD's Special Programme on Insurance, New York, United Nations, UNCTAD/INS/99, 1986.
} 
In the resolution, the Conference specifically:

"Affirmed that developing countries should take steps to enable their domestic insurance markets to cover in these markets - taking into account their national economic interests and the insured interests - the insurance operations generated by their economic activities, including their foreign trade, as far as technically fcasible;

Considered that developing countries might achicve these objectives by establishing and strengthening domestic insurance and reinsurance organizations, where the size of the insurance market permits it;

Recommended that developing countries should take steps to ensure that technical reserves accruing from insurance and rcinsurance operations carricd out in their countries are invested in the same countries, taking into account all the relevant characteristics and technical requirements of the risks involved and the kind of insurance and reinsurance cover provided, as well as the criteria of security, liquidity and income;

Recommended that nationals of developed countries, when investing in developing countries, should, while observing the requirement of national legislations, call upon the insurance services of these countries' national insurance markets, whenever these markets can provide appropriate cover;

Recommended that developing countries should establish closer co-operation between their insurance and reinsurance institutions on a regional and/or subregional basis ;

Invited Governments of developed countries to continue, and where appropriate, increase the technical assistance and training facilities which they provide to developing countries in order to assist in developing thcir domestic insurance and reinsurance systems. Insurance and reinsurance institutions of member countries are also invited to continue and, if possible, expand their technical assistance efforts."

This change in emphasis is a reflection of the growing awareness in the developing countries of their own responsibility in the development process. In the field of insurance they recognized implicitly that a better utilization of their own resources and internal means could play an important role in that process.

\subsection{The activities of the insurance programme}

To assist developing countries in achieving the above objectives, the UNCTAD Insurance Programme undertakes studies, provides technical assistance and participates and organizes training and cducational activities.

No developing region is without its problems in regard to insurance and rcinsurance. Some of these problems are inherent to the very nature of insurance when practised on a relatively small scale, with restricted financial means and insufficient know-how and expertise; others are gencrated by external events of which insurance has to bear the consequences. But all developing countries are faced with essentially the same problems at varying degrees of importance and intensity.

Studies are carricd out by the UNCTAD secretariat with a view to contribute in finding adequate solutions for the developing countries. The main topics studicd include:

(a) Introduction of appropriate insurance legislation and supcrvision;

(b) Investment of tcchnical reserves of insurance concerns in the country where the premium arises; 
(c) The principle of local insurance for local risks;

(d) Measures designed to improve the performance of insurance companies in developing countries;

(e) Adaptation of insurance guarantees to the real needs of the country, taking into consideration its culture and socio-economic environment;

(f) Reinsurance;

(g) Risk management and loss prevention;

(h) Insurance education and training;

(i) Role of services in the development process;

(j) Statistics.

All studies (see Annex I) were presented at different sessions of the Committee on Invisibles and Financing related to Trade and are available upon request.

Besides being responsible for the conduct of studies, UNCTAD assists Governments of developing countries individually and collectively in their development efforts through technical assistance. A request for assistance always emanates from the Government itself. This assistance at the individual Government level has included advising Governments on the feasibility of establishing and strengthening national insurance and reinsurance organizations. UNCTAD has also been requested at various times to revise existing insurance legislation or draw up new legislation appropriate to the needs of the country.

\section{Human resources development in the field of insurance}

The assumption is that, with appropriate personnel, developing countries could develop sound national insurance markets in which national companies would play a dominant role. On the occasion of the Sixth Meeting in July 1973 of the Committee on Invisibles and Financing related to Trade, the attention of the members of the Committee was drawn to the need to promote training of technically skilled staff and to elaborate programmes for such training according to the present and future requirements of developing countries.

In examining these issues, at the present juncture, one must consider the rapid transformation of insurance markets since changes have occurred in the policy orientation adopted by many developing countries, particularly orientation towards competitive markets through privatization and/or liberalization. The most obvious implications for the future of this industry are both improvements in the technical excellence of those engaged in insurance activities and adaptation of training facilities to the growing demand for trained people.

One of the principal problems facing developing countries is the lack of qualified manpower. The insurance sector is no exception. The lack of qualified personnel in this sector not only affects the companies, but is also a source of difficulty for supervisory offices entrusted with drawing up national sectoral policics, drafting regulations, facilitating development, laying down standards and ensuring supervision of the sector.

Educational requirements and the nced to introduce appropriate occupational training are acknowledged to be the top priority in the 1990s.

\subsection{International co-operation in training and human resources development}

It is recognized by all specialists that the benefits of capital creation are marginal if the necessary human resources are not present to organize and move the economy forward. High priority should be placed on the availability of well-designed certification programmes 
in every country. The needs may not be the same in all developing countries and so they cannot be met simply by importing the programmes which developed countries have already established.

It is not enough simply to build or open training institutions or centres, but rather in each sector of a country's economy there is a need to integrate training programmes with comprehensive human resources strategies including resource planning, definition of training policies and career development for the whole range of personnel categories.

Possibilities for co-operation do exist. It can be based on the exchange and adaptation of materials, the transfer of resources and the training of trainers. This was the conclusion and recommendation of the first seminar on Human Resources Development in the field of Insurance organized by UNCTAD in Lisbon, Portugal in November $1990 .^{2}$

The main purpose of the international co-operation network would be to provide the developing countries with high-quality teaching materials, for use by qualified trainers, i.e. provide the right training for the right people (Couroux, 1990). The approach is now being developed by UNCTAD with a programme called TRAINFORTRADE (Training Development in the field of Foreign Trade) and is designed to strengthen capacities in developing countries for the development of human resources in the field of foreign trade.

TRAINFORTRADE aims at (i) producing in co-operation with selected institutions a series of training packages covering the needs of "practitioners" in the public and private sectors related to international trade, and (ii) establishing a self-sustaining network of cooperation among the selected institutions through the exchange of training material and training staff.

The subjects to be covered already include components of marine insurance and risk management but it is expected that the development of trade in services would increase the need for training programmes in insurance and financial services.

\subsection{The promotion of risk management in developing countries}

Insurance has become qualitatively more important, owing to the higher risks and uncertainties of modern societies.

The reasons for greater uncertainty may largely be attributed to side effects from the technological base on which the structure of modern societies rests. The changing patterns of risk and of attitudes towards risks, the optimal use of insurance and financial instruments as a means of dealing with risks and uncertainties and the efficient management of financial institutions have become major concerns.

Despite this growth, insurance specialists generally complain that the insurance industry in most countries of the world has been suffering an image problem in the eyes of the public. Such a situation appears to have the same causes in both developed and developing countries. The fundamental reasons are certainly due to an inadequate perception of the real importance of insurance and of its risk management role (Outrevillc, 1190).

A study on the promotion of risk management in developing countries was presented at the Committee on Invisibles and Financing related to Trade in March 1987. The Committee

2 UNCTAD, Human Resources Development in the field of Insurance, New York: United Nations, UNCTAD / RDP / INS / 1, 1991. 
adopted a resolution recognizing that regional and international organizations, governments and all interested professional and non-governmental organizations should assist in the promotion of risk management (Annex II).

At present, it is unrealistic to expect risk management specialists to emerge in most developing countries. It is, therefore, all the more important to have co-operation among the various interested and affected entities and to draw from the available international expertise. At the regional and national level, educational and training institutions can be expected to contribute significantly to risk management practice and knowledge through adapted education and training programmes.

\subsection{Insurance supervision in developing countries: a case for human resources development}

There is today general agreement that insurance supervision is a fundamental requirement for the sound development of insurance activities, and that insurance activities, properly supervised, play an important role in the process of economic growth of every country. The principle of state intervention has been generally recognized and adopted in almost all countries. When the volume of insurance transactions reaches a certain level, legislation must be enacted to provide some degree of supervision of insurance activities. The few exceptions which exist do not invalidate the rule.

The growth of the insurance industry and the increasing sophistication of the markets require the presence of an efficient body of supervision. Since the developing countries have been moving progressively towards more detailed supervision of the operations of insurance concerns, administrative services responsible for the supervision are becoming better equipped to cope with complex tasks. Where the supervisory services are for whatever reason unable to carry out the tasks for which they were set up, the resulting distortions are likely to render the law inoperative; the purpose of legislation is thus then frustrated.

If the supervisory personnel is highly qualified, both personally and professionally, it can become, especially in developing countries, one of the main instruments available to the state for promoting the national development of the insurance business. Such heavy responsibility calls for, as a corollary, high technical education and qualifications on the part of the staff of the insurance supervisory authorities. This was recognized by the Committee on Invisibles and Financing related to Trade at its last session in February 1990 which invited UNCTAD "to take the necessary steps to prepare a detailed programme for education and training of qualified personnel of supervisory offices in developing countries" (Annex III).

\section{General remarks and conclusions}

From its roots in the mandate established by the General assembly, the role of UNCTAD has evolved under the guidance of successive sessions of the Conference and UNCTAD has responded to changing conditions, needs and orientations while maintaining its universal character and its development mission.

The developmental vision of UNCTAD's work in insurance permits the organisation's technical cooperation activities, which seek to increase the ability of developing countries to overcome structural and technical constraints, including the lack of know-how, which inhibits the development of a sufficient domestic insurance capacity and its progressive integration into world trade activities. 
Human resources development in the field of insurance, as in any discipline, must be broad rather than purely technical. It must encompass not only the legal and social context in which the industry works, but also reflect an awareness of standards of behaviour which are integral to the sound practicc of a service industry such as insurance. The connection between education and professionalism is vital to the insurance industry's operation and credibility with the public.

Positive conditions exist for strengthening international co-operation for development and promoting co-operation among developing countries. Nonetheless, substantial obstacles remain. Participation in the benefits of economic expansion and technological advance is still unequal and the problems of the least developed countries are particularly acute. It is of utmost importance to promote the development of insurance markets through a deliberate attempt to link as far as possible operational activitics with the research and analytical work.

In conclusion, it would be fair to state that, while the great majority of insurance markets in the Third World may face the 1990s with confidencc and with good prospects for growth and consolidation, considerable efforts will be necessary to increase local expertise in those markets in order to avoid the pitfalls of external reliance and to improve their technical and economic performance.

\section{REFERENCES}

COUROUX, M. "International Technical Co-operation in training and human resources development" in UNCTAD, Human Resources Development in the field of insurance, New York, United Nations, UNCTAD / RDP / INS. 1, 1991.

OUTREVILLE, J. F. "The Role of insurance education in Colleges and Universities", in UNCTAD, Human Resources Development in the field of insurance, New York, United Nations, UNCTAD / RDP/INS. 1, 1991. 


\section{ANNEX I \\ List of studies prepared by the Programme on Insurance}

Insurance legislation and supervision in developing countries (TD/B/C.3/84/Rev. 1, Add. 1 and 2, 1972).

Establishment of a unified international system of insurance statistics (TD/B/C.3/85/Rev.l, 1972).

Investment of technical reserves of insurance concerns in the country where the premium incone arises (TD/B/C.3/87, 1972).

Reinsurance problems in developing countries (TD/B/C.3/106/Rev.1, 1973).

Marine cargo insurance (TD/B/C.3/120, 1975).

Insurance education for developing countries (TD/B/C.3/121 and Supp. 1, 1975).

Insurance of large risks in developing countries (TD/B/C.3/137, 1977).

Co-operative insurance: a suitable form of insurance for developing countries (TD/B/C.3/138, 1977).

Cargo insurance problems in land-locked developing countries (TD/B/C.3/140, 1977).

Methods used for increasing the local retention of insurance business: regional and national pools (TD/B/C.3/160, 1980)

Loss prevention in fire and marine cargo insurance (TD/B/C.3/162, 1980).

Crop insurance for developing countries (TD/B/C.3/163/Rev.1, 1980).

Third world insurance at the end of the 1970s (TD/B/C.3/169/Add.1, 1980).

Cargo loss prevention: suggestions for a domestic policy in developing countries (TD/B/C.3/162/ Supp.1, 1982).

Legal and documentary aspects of the marine insurance contract (TD/B/C.4/ISL/27, 1982).

Motor insurance in developing countries (TD/B/C.3/176 and TD/B/C.3/176/Supp.1, 1982), (TD/B/ C.3/190 and $\mathrm{TD} / \mathrm{B} / \mathrm{C} .3 / 191,1985)$. The four studies are issued in one volume entitled: Motor Insurance Compensation of Motor Accident Victims in the Developing Countries (TD/B/C.3/209) United Nations Sales publication, Sales No. E.85.II.D.

The promotion of life insurance in developing countries (TD/B/C.3/177, 1982).

Establishing life insurance tax policy in developing countries (TD/B/C.3/193, 1985).

Insurance in the context of services and the development process (TD/B/1014, 1984).

The impact of captive insurance companies on the insurance markets of developing countries (TD/B/ C. $3 / 192,1985)$

The promotion of risk management in developing countries (TD/B/C.3/218 and Add.1, 1987).

UNCTAD model clauses on marine hull and cargo insurance (TD/B/C.4/ISL/50, 1989).

Reinsurance security (TD/B/C.3/221/Supp.1, 1987).

Reinsurance security for developing countries (TD/B/C.3/228, 1989).

Statistical survey on insurance and reinsurance operations in developing countries (TD/B/C.3/220, 1987, and TD/B/C.3/231, 1990).

Review of developments in insurance and reinsurance in developing countries

(TD/B/C.3/99, 1970)

(TD/B/C.3/107, 1971-1972)

(TD/B/C.3/122, 1973-1974)

(TD/B/C.3/141, 1975-1976)

(TD/B/C.3/169, 1977-1979)

(TD/B/C.3/178, 1980-1981)

(TD/B/C.3/189, 1982-1983)

(TD/B/C.3/222, 1984-1985)

(TD/B/C.3/229, 1986-1988) 


\section{ANNEX II}

6 march 1987

31 (XII). Risk management in developing countries. The Committee on Invisibles and Financing related to Trade,

Recalling resolution 27 (XI), which was adopted by the Committee at its eleventh session on 22 February 1985 and emphasized that it is to the advantage of the economies of developing countries to prevent losses associated with the commercial and industrial enterprises located in those countries and to reduce the severity of losses associated with such enterprises

Recalling in particular the role that can be played by modern risk management techniques, including the identification and assessment of risks, prevention, risk financing and the role of insurance in providing cover for such risks.

Taking note with great interest and appreciation of the study presented by the UNCTAD secretariat entitled "The promotion of risk management in developing countries" (TD/B/C.3/218 and TD/B/ C. $3 / 218 /$ Add.1),

Recognizing that successful promotion of risk management requires the endorsement and active support of Governments and that concerted effort is needed at the local, regional and international level,

Recognizing also that regional and international organizations and other interested professional and non-governmental organizations should assist in risk management promotion,

1. Considers that the aforementioned study presented by the UNCTAD secretariat provides valuable guidance as regards the promotion of modern risk management techniques in developing countries and the role that can be played by Governments, commercial and industrial enterprises, the insurance industry and other groups and organizations described in the above-mentioned study;

2. Agrees that the suggested measures may bring benefits to developing countries and also to the insurance sector on an international scale and to other interests concerned, and therefore recommends that the developing countries use on a broader scale these risk management techniques in accordance with their national requirements and that the developed countries and all other countries in a position to do so support the efforts for promotion of modern risk management techniques in developing countries;

3. Requests the United Nations agencies to extend their co-ordination on this subject:

4. Invites countries in a position to do so to keep the UNCTAD secretariat informed of measures and of results obtained, so that the information thus received can be made available to all interested countries and especially the developing countries:

5. Recommends the developing countries make use of the competence of the UNCTAD secretariat to provide technical assistance in the field of the promotion of risk management. 
33 (XIII). Review of developments in the field of insurance and reinsurance review of the work programme of the Committee

The Committee on Invisibles and Financing related to Trade,

Recalling the recommendation on insurance and reinsurance in annex A.IV.23 to the Final Act adopted by the United Nations Conference on Trade and Development at its first session, in which it was agreed, inter alia, that a sound national insurance and reinsurance market is an essential characteristic of economic growth,

Recalling also resolution 42 (III) adopted by the United Nations Conference on Trade and Development on 17 May 1972, in which the Conference, inter alia, affirmed that developing countries should take steps to enable their domestic insurance markets to cover in these markets - taking into account their national economic interests as well as the insured interests - the insurance operations generated by their economic activities, including their foreign trade, as far as is technically feasible,

Further recalling resolution 19 (IX) adopted by the Committee at its ninth session on 3 October 1980 , in which it was agreed, inter alia, that it is necessary to extend and intensify efforts to achieve greater retention in developing countries and that these efforts should take into account the varying characteristics of individual market situations,

Recognizing that most developing countries have succeeded in building up an insurance industry with local supervision and that progress has been achieved in the development of the different insurance sectors in these countries during the Second and Third United Nations Development Decades,

Taking note with interest and appreciation of the report by the UNCTAD secretariat entitled "Insurance in developing countries: review of developments in 1986-1988" (TD/B/C.3/229),

Cognizant of the rapid transformation of insurance markets due to changes in policy orientation adopted by many countries and bearing in mind that this evolution may reflect on the attainments achieved by a number of developing countries in the strengthening of their domestic markets,

Considering that effective prudential regulation and supervision are essential for the sound development of insurance activities,

1. Urges developing countries to continue to intensify their efforts to promote and consolidate their domestic insurance sectors so that a strong and healthy insurance industry will continue to play its vital economic role;

2. Invites developing countries to consider measures, including steps for multilateral co-operation as may be appropriate in their individual circumstances, to increase the financial strength of the companies in their markets and the role and effectiveness of the supervisory system;

3. Calls upon the UNCTAD secretariat;

(a) To review developments in insurance markets and to analyse their impact in order to provide new insights which could prove useful to policy-makers in developing countries;

(b) To undertake a study on effective prudential insurance regulation and supervision in developing countries;

(c) To take the necessary steps to prepare a detailed programme for education and training of qualified personnel of supervisory offices in developing countries;

(d) To prepare a study on the possibilities for increasing insurance awareness in developing countries and in particular for extending insurance cover to productive entities in the traditional sector, with particular reference to agricultural production, by devising appropriate insurance covers and taking into account the work done in other organizations; 
4. Stresses the need to establish closer co-operation between the insurance supervisory services of developing countries, as well as between their insurance training institutions, on a regional and/or subregional basis, where appropriate;

5. Invites developing countries to envisage ways of co-operating among themselves with a view to increasing business exchange in the field of insurance and reinsurance;

6. Invites all countries and non-governmental organizations which are in a position to do so, taking into account the mandate of UNCTAD in the field of insurance, to consider:

(i) Continuing to provide technical assistance to developing countries in the field of insurance and reinsurance, and particularly for the purpose of implementing training courses and seminars for the staff of insurance supervisory offices;

(ii) Supporting and co-operating in the organization of regional meetings for insurance supervisors and insurance educators for the purpose of exchanging information and experience regarding inarket changes, insurance supervision and training programmes. 